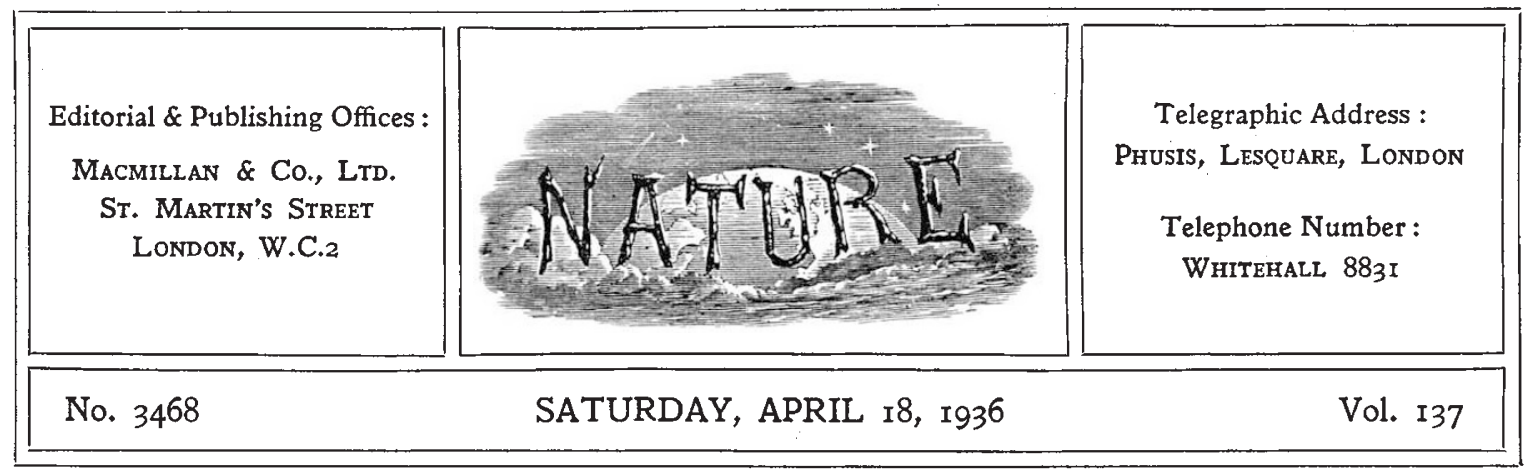

\title{
The Delusion of Race
}

$\mathrm{R}^{\mathrm{s}}$ ACE classification, it has been asserted by an authority of no little experience, is the most difficult of the tasks of the anthropologist. The difficulties of the man of science in connexion with a technical point are not, as a rule, of immediate concern outside professional circles; but in this instance the inability of the anthropologists to clarify opinion by a generally acceptable definition of 'race', and their failure to arrive at an agreement as to its implications have had serious repercussions in the outside world, as is now familiar to everyone. Extreme and biased views have been accepted as endorsed by science because no voice is raised to contradict them with full and unquestioned authority.

It is unfortunate that striking distinctions between peoples and between individual members of population groups, which are immediately obvious, should afford ground for popular judgment on questions of race, upon which the anthropologist, with full technical equipment, hesitates to arrive at a final conclusion. It is still more unfortunate that, so far from the disparity between the hesitancy of science and the dogmatic certainty of popular opinion being a matter of merely academic interest, up to the present the popular judgment has prevailed in practical affairs. Racial distinctions have emerged from the sphere of intellectual inquiry and have been made the practical basis of discrimination and a justification for actions such as social ostracism, legal disability and group persecution which have brought disaster to society and the individual throughout the whole course of history.

It is, of course, patent to anyone familiar with the analytic methods of the scientific study of peoples and population groups that the popular judgment in racial matters is in fact based on a composite body of evidence. It is usually initiated by the stimulus of certain obvious and distinctive physical characters exhibited in the individual. More often than not, one character only is taken into account, such as colour ; and this is reinforced and confirmed by the interpretation of other characters, which the more precise diagnosis of science assigns to the influence of one or other of at least three factors-race (in the sense of the inheritance of certain physical characters and also, presumably, certain mental qualities, though on the latter most anthropologists would hesitate to dogmatise), environment and culture. Of the two latter, one stands for the physical conditions, the other for the social and material circumstances in which the individual organism has developed and by which it has been moulded while plastic.

The precise determination of the respective spheres of the influence of the three factors - race, environment and culture - is often difficult to discern; but owing to the failure of the popular judgment to discriminate, even on broad lines, between the parts played by them in the lifehistory of the individual and the group, there arise such popular confusions as that between nationality and race, as in the fallacy of the 'French race', or between linguistic affinity and race, which is responsible for the 'Latin races' and the 'Celtic race', or in the mistaken identification of a cultural quality as racial, as for example colour preference in dress, or even gesture or intonation in speech.

However much the more instructed observer may attempt to discount their influence, there is no doubt that cultural characters play a large, but not always consciously realised, part in racial identifications, which do not depend upon exact 
measurement. The conscientious anthropologist, however, would hesitate to say at present whether or not some of such cultural characters may have a diagnostic value in racial discrimination, in a broad sense, between discrete groups-in other words, how far, if at all, culture is a function of race. A priori argument might well maintain that a specific culture is as much a product of the discriminatory process of natural selection as the evolved race by which it has been developed.

The difficulties of the problem, of which not a tithe of the more obvious are here suggested, may be gauged from the fact that a committee of the Royal Anthropological Institute and the Institute of Sociology, appointed in April 1934 to frame a simple definition of race to serve as a guide to the general public in the discussion of the problems of to-day and to indicate the relations of race and culture, has only now reached the stage of an interim report* dealing with the definition of race. The committee had for chairman Sir Grafton Elliot Smith and later Prof. H. J. Fleure. Its members are distinguished anthropologists and biologists, and include Profs. J. B. S. Haldane, Ruggles Gates and Le Gros Clark, and Dr. G. M. Morant. Even after this term of deliberation, which it may not be regarded as unfair in the circumstances to designate 'lengthy', the committee was not able to arrive at complete agreement. Not only are alternative definitions offered, but also several members append independent observations which at times almost amount to minority reports.

The definition of race put forward by the committee is as follows:

"A Race is composed of one or more interbreeding groups of individuals and their descendants, possessing in common a number of innate characteristics which distinguish them from other groups. The innate characteristics mentioned are held to be such as usually apply to the generality of the individuals studied, and not to be pathological characters, or features (such as red hair) which characterise only a relatively small percentage in a population. In the present state of our knowledge we are dependent on characters recognised as physical for the purpose of differentiating races, though innate psychological characters may later be found to differentiate them."

The alternative definition preferred by some members is :

"By race is meant a biological group or stock possessing in common an undetermined number of

* Race and Culture. Pp. 24. (London: Le Play House Press ; Royal Anthropological Institute, 1936.) 18. associated genetical characteristics by which it can be distinguished from other groups and by which its descendants will be distinguished under conditions of continuous isolation (that is, so long as the stock is preserved against internal dilution)."

These definitions are unexceptionable, each in its respective field and so far as it goes. The second is perhaps to be preferred, as it brings the study of man more nearly into relation with the present trend of biological research in other fields. In view, however, of the special purpose of the committee to provide assistance for the general public in current discussion, certain limitations might have been pointed out. In so far as the races of man are concerned, these definitions, far from being generalisations from concrete realities and empirical, are no more than logical concepts, postulated for purposes of classification and investigation. In face of the actual facts of the distribution of physical characters among the population groups of the world, as they exist at the present moment, race is a pure abstraction. The races or types into which the anthropologist groups the varieties of Homo sapiens are ideal types built up to explain congeries of characters in individuals and groups, derivative from a variety of strains, in some sort of a phylogeny. Man seems to be almost infinitely variable within a wide range, and since upper palæolithic times in the course of world-wide migration has interbred freely, with the result that the ideal types of anthropological classification, if they ever existed at all in any degree of purity, have become a matter of faith rather than of evidence. Characters on which classifications have been based are found everywhere to overlap, and both individual and population group bear witness to their inextricably mixed descent.

Modern facilities of transport have naturally added considerably to the trials of the anthropologist. Some indications of the combinations in breeds and the complicated character of the results within a comparatively short period is afforded by conditions in South Africa, of which an interesting account is given in a study of some racial crosses to be seen there by Prof. H. B. Fantham, now of McGill University and formerly professor of zoology in the Witwatersrand University, Johannesburg (see p. 665). In South Africa, as has been shown by recent discussion of the native 'Cape franchise' in the Union Parliament, the racial question is acute. It has the somewhat peculiar feature that the policy of segregation adopted by the white population as a protective measure against the 
domination of the black by force of numbers, is also strongly supported by the latter, or at least its better elements. On both sides there is a fear of racial deterioration and degradation. It is interesting, therefore, to see what are the actual results of some of the crossings which have come under Prof. Fantham's observation.

A family which arose from a Dutch-Xosa miscegenation, repeated by one son, while other children married 'Cape coloured', consisted of fifteen individuals in two generations, who varied from black to three nembers who pass as white. The hair varied from frizzy or crimpy to fairly straight. The white members are described as "more temperamental". Anether family, also of DutchXosa origin, investigated in three filial generations, shows the same variation in pigmentation, feature and hair form between the European and the black parent; while the most marked range of variation is shown, as might be expected, by the intermarriage of two families, who had a mixed descent of Portuguese, Dutch, Huguenot, Basuto and Javanese (Malay).

The interest of these studies, of course, is that they are a precise and exact record of a state of affairs which is known to have been in being since the sixteenth century, when the whites first began to come in numbers to the Cape. Further, the native peoples with whom the whites intermarried were not themselves 'pure'. Not only had they interbred freely, or at least with some freedom, but also some of them had been in contact with Arabs and other early visitors to Africa.

South Africa, however, is not singular in this matter of racial crossing, though the facts can perhaps be followed there with greater certainty than in some other parts of the world. The conditions there, in fact, reproduce what has been taking place on a greater or lesser scale in all parts of the world since man first began to move about at all freely. The remarkable results noted by Prof. Fantham and the records of other observers go to show how it has come about that individuals and populations, when submitted to detailed examination; exhibit combinations of characters which set precise classification at defiance, if more than a very limited range of characters is taken into account. This fact certainly lends every support to those who would maintain that the significance attached to race in current political argument is a delusion which, in its inflammatory tendencies, is fraught with no little danger.

\section{The Art of Plant Description}

Phytography as a Fine Art:

Comprising Linnean Description, Micrography and Penportraits. By Dr. J. W. Moll. Pp. xix +534 . (Leyden: E. J. Brill, Ltd., 1934.) 15 guilders.

THE late Prof. Moll's book on phytography is remarkable in several respects. Written between the ages of seventy-two and eighty-two years by a blind man suffering from gradually increasing deafness, with the aid of three successive secretaries and the use of Braille, it represents a triumph of human will-power and endurance over grave bodily disabilities: The subject of the work is stated to be the improvement of the art of phytography in all possible directions. The book actually consists, however, of a highly complex morphological system by the aid of which a fairly adequate description may be drawn up in a more or less mechanical way, even by a botanist who possesses little or no natural aptitude for the task. The system is valuable also to the skilled describer, since it may frequently serve as a reminder to include essential characters which might otherwise be easily overlooked.

The monumental nature of this system is illus. trated by the author's statement that "a complete pen-portrait of a higher plant will easily take a man's work during a whole year". On this basis, the completion of a work comprising the penportraits of all known plants would cost at least 150,000 years of a man's working life : even with 1,000 collaborators it would still take 150 years. This amounts to an impossibility, and it seems clear that the description of the plant world will continue to proceed largely by means of those approximately accurate generalisations regarding taxonomic groups commonly called 'descriptions' of sections, genera, tribes, families, etc. Indeed, one of the earliest lessons that the budding taxonomist should learn is to exclude wellestablished generic characters from his specific descriptions.

The volume is divided into five 'books', the first (pp. 3-22) being introductory. The value of the 